\title{
Evaporation Behavior of Non-gaseous Fission Products from $\mathrm{UO}_{2}$
}

\author{
J. TAKAGI * \\ NAIG Nuclear Research Laboratory, Kawasaki, Japan \\ (Z. Naturforschg. 20 a, 1566-1568 [1965] ; received 28 June 1965)
}

\begin{abstract}
The evaporation behavior of non-gaseous fission products from $\mathrm{UO}_{2}$ was studied. The release rate of non-gaseous fission products during the post-irradiation annealing of $\mathrm{UO}_{2}$ was found to be controlled by the proportionality constant of evaporation, $a$, as well as the diffusion constant. The values of $\alpha$ for $\mathrm{Ru}, \mathrm{Ce}, \mathrm{La}, \mathrm{Mo}$ and Te were determined at temperatures ranging 750 to $1600^{\circ} \mathrm{C}$ and the general method of treating non-gaseous fission product release from $\mathrm{UO}_{2}$ was discussed.
\end{abstract}

Zumwalt et al. ${ }^{1}$ have reported the diffusion constants of $\mathrm{I}, \mathrm{Te}$ and $\mathrm{Ba}$ in $\mathrm{UC}_{2}$ single crystals, while Or and the author ${ }^{2,3}$ have measured the diffusion constants of various non-gaseous fission products in $\mathrm{UO}_{2}$ single crystals. In these works, the diffusion was studied by application of the method usually used for the determination of the diffusion of gaseous fission products, $\mathrm{Kr}$ and $\mathrm{Xe}^{4,5}$, where the fractional release $F$ of the fission products from a sphere of radius $a$ is given by

$$
F=1-\frac{6}{\pi^{2}} \sum_{n=1}^{\infty} \frac{1}{n^{2}} e^{-D n^{2} \pi^{2} t / a^{2}},
$$

$D$; diffusion constant, $t$; annealing time.

However ${ }^{3}$, when the surface evaporation condition

$$
-D \frac{\partial C}{\partial r}=a C \quad \text { (surface) }
$$

$\alpha$; proportionality constant of evaporation, is taken into consideration ${ }^{6,7}$, the fractional release should be given by the equation

$$
\begin{aligned}
& F=1-\sum_{n=1}^{\infty} \frac{6 L^{2} e^{-\beta_{n}^{2} D t / a^{2}}}{\beta_{n}^{2}\left\{\beta_{n}^{2}+L(L-1)\right\}}, \\
& L=\frac{a \alpha}{D}, \quad \beta_{n} \cot \beta_{n}+L-1=0 .
\end{aligned}
$$

For the single crystals with equivalent radii of $0.3-0.7 \mathrm{~mm}$ used in the previous works, equ. (1) was assumed to hold for reasons to be mentioned later on in this paper. The data obtained in this way

* Present Address: Institute for Nuclear Study, University of Tokyo, Tanashi-machi, Kitatama-gun, Tokyo, Japan.

1 L. R. Zumwalt, P. E. Gebhard, and E. E. Anderson, Nucl. Sci. Eng. 21, 1 [1965].

2 N. Or and J. Takagi, Z. Naturforschg. 19 a, 1331 [1964].

3 N. Oi and J. TAKAGI, Z. Naturforschg. 20 a, 673 [1965].

4 F. Felix, T. Lagerwall, P. Schmeling, and D. E. Zimen, 3rd A/Conf. 28/P/472, United Nations 1964. from equ. (1) are listed in Table 1 for various fission products, among which the values for $\mathrm{Ru}, \mathrm{Ce}$, $\mathrm{Sr}$ and $\mathrm{Zr}-\mathrm{Nb}$ result from the previous ones and additional experiments.

\begin{tabular}{|c|c|c|}
\hline Nuclides & $D_{0}\left(\mathrm{~cm}^{2} / \mathrm{sec}\right)$ & $Q$ (cal/g $\cdot$ atom $)$ \\
\hline${ }^{106} \mathrm{Ru}$ & $5.5 \times 10^{-7}$ & 27,000 \\
${ }^{144} \mathrm{Ce}$ & $1.2 \times 10^{-4}$ & 50,000 \\
${ }^{90 \mathrm{Sr}}$ & $1.0 \times 10^{-6}$ & 27,000 \\
$95 \mathrm{Zr}-{ }^{95} \mathrm{Nb}$ & $2.4 \times 10^{-2}$ & 92,000 \\
$131,2 \mathrm{~J}$ & $1.5 \times 10^{-3}$ & 59,000 \\
$99 \mathrm{Mo}$ & $3.9 \times 10^{-4}$ & 54,000 \\
$132 \mathrm{Te}$ & $6.6 \times 10^{-3}$ & 70,000 \\
$140 \mathrm{La}$ & $2.2 \times 10^{-6}$ & 35,000 \\
\hline
\end{tabular}

Table 1. $D$ values obtained by single crystals $(a=0.3-0.7 \mathrm{~mm})$.

On the other hand, the fractional release of nongaseous fission products from $\mathrm{UO}_{2}$ samples consisting of grains with much smaller radii $(0.055 \mu)$ proved to be fairly smaller than expected from equ. (1) with the $D$ 's of Table 1 . This suppressed release arises from the slow evaporation of non-gaseous fission products and is successfully explained by equ. (2) with suitably chosen $L$ values. An attempt is made to clarify the release behavior of non-gaseous fission products by determining evaporation rate coefficient $\alpha$ for Ru, Ce, La, Te and Mo. The treatment will present a general method applicable to systems where non-diffusional transfers of fission products like initial burst ${ }^{4}$ and trapping ${ }^{8}$ are negligible.

5 HJ. Matzke and R. Lindner, Atomkernenergie 9, 2 [1964].

${ }^{6}$ H. S. Carslow and J. C. J Aeger, Conduction of Heat in Solids, Chap. 9, Oxford Univ. Press, Oxford 1947.

7 J. Crank, Mathematics of Diffusion, Chap. VI, Oxford Univ. Press, Oxford 1956.

8 R. M. Caroll, R. B. Perez, and O. Sisman, J. Amer. Ceram. Soc. 48, 58 [1956]. 


\section{Experimental}

The $\mathrm{UO}_{2}$ powders obtained from DEGUSSA (Germany) consisted of crystal grains with an average radius $0.055 \mu$ which suffered significant growth when heated over $1000^{\circ} \mathrm{C}$. The grain size at each temperature of annealing was measured by the BET and electron microscopic method. It was confirmed by $\mathrm{OI}^{9}$ that the release of $\mathrm{Xe}$ from the samples satisfies eq. (1) only if corrections for the increase of $a$ are made.

Each $10-20 \mathrm{mg}$ of the $\mathrm{UO}_{2}$ powder irradiated in TTR-1 $\left(n v t, 1.5 \times 10^{15} \mathrm{n} / \mathrm{cm}^{2}\right)$ or in JRR-2 ( $n v t$. $5 \times 10^{16} \mathrm{n} / \mathrm{cm}^{2}$ ) and cooled for $1-8$ weeks was heated in a platinum boat by a tungsten filament. The heating continued for 10-60 min under a constant flow of $\mathrm{He}$ $\left(\sim 1 \mathrm{~m} / \mathrm{min}\right.$ at the sample position) at $750{ }^{\circ} \mathrm{C}$ to $1600{ }^{\circ} \mathrm{C}$. $\gamma$-ray spectra were taken for each sample before and after the heating and the fractional release was calculated from the difference of the activities for each fission product examined.

\section{Results and Discussions}

(1) Equation (2) implies that the fractional release depends not only upon the diffusion constant $D$ but upon the parameter $L$ which is also a function of the evaporation rate coefficient $\alpha$. $F$ increases

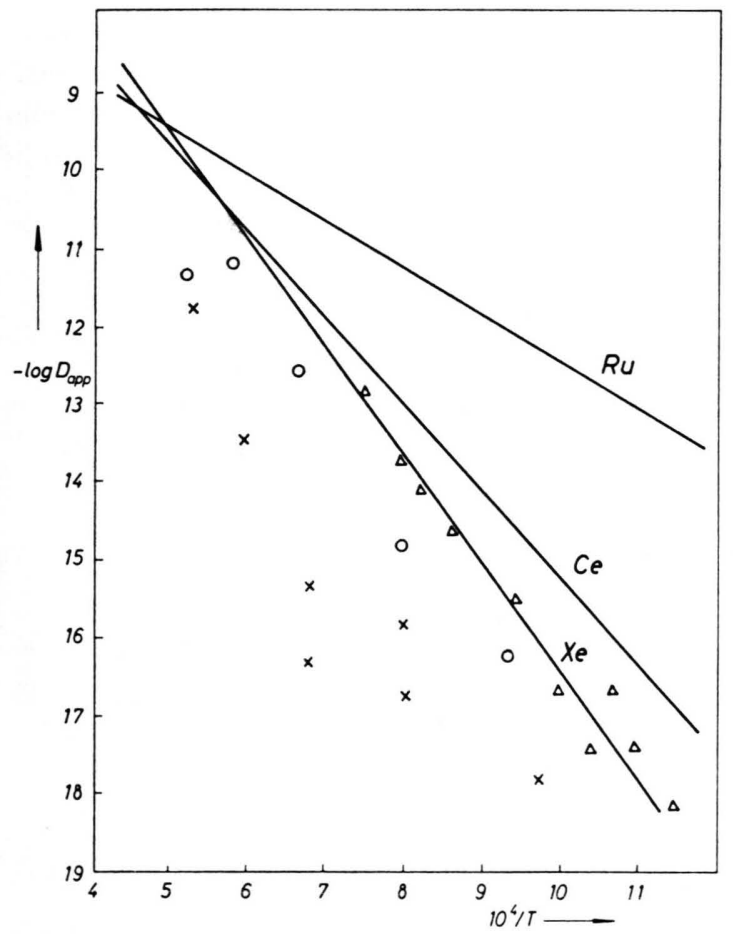

Fig. 1. $D$ values calculated from Table 1 (solid lines) and apparent $D$ values obtained by application of eq. (1) on fine $\mathrm{UO}_{2}$ powders $(\triangle \ldots \mathrm{Xe}, \bigcirc \ldots \mathrm{Ru}, \times \ldots \mathrm{Ce})$. with $L$ and in the limit of $L \rightarrow \infty$, equ. (2) reduces to equ. (1), which means that the evaporation is so rapid that the release rate is determined by diffusion alone. Solutions of equation (2) for some $L$ values are tabulated in the literature ${ }^{10}$.

For small $a$ and therefore small $L$ the results obtained by application of equ. (2) differ much from those obtained from equ. (1). An example is illustrated in Fig. 1 for Ru and Ce. The phenomena can not be ascribed to structural differences between the two kinds of specimen, since the release of $\mathrm{Xe}$ follows equ. (1) in both cases.

With the observed $F$ values and the $D$ values of Table 1 the values of $\alpha$ were evaluated for each fission product and at each temperature investigated. For this purpose $F$ vs $L(0.1 \leqq L \leqq 100)$ was plotted for experimentally given $\sqrt{D t / a^{2}}$ values. This was performed by computing the summation of equ. (2) up to the term $n=2$, and by solving

$$
\beta_{n} \cot \beta_{n}+L-1=0
$$

graphically. The errors of this method of estimation are quite small as compared with the experimental scatters.

In most cases, $L$ was found to lie below 0.1 . In these cases, the $\alpha$ was calculated independently of $D$ by the following approximation

$$
\beta_{1}=\sqrt{3 L}, \quad F=1-\exp \left(-\frac{3 a t}{a}\right)
$$

Fig. 2 shows Arrhenius plots of $\alpha$ 's for the five fission products examined. Generally, $\alpha$ may be written in the form $\alpha=\alpha_{0} \exp \left(-E_{\alpha} / R T\right)$, where $E_{a}$ is the activation energy of evaporation. The observed values of $E_{a}$ are listed in Table 2 along with the melting points and boiling points of the metals. Although little significance is attributed to the absolute values of $\alpha$, as they may change with experimental conditions, e. g. sweep gas flow rate ${ }^{11}, \alpha$ can serve as a measure of the relative evaporation behavior of various fission products from $\mathrm{UO}_{2}$ (Table $3)$. Furthermore, $E_{\alpha}$ will be of help in identifying the evaporating species: observed small values might suggest the formation of some volatile compound. Detailed investigations on the in-pile evaporation

9 N. Or, Z. Naturforschg. 20 a, 1569 [1965].

10 A. B. Newman, Trans. Amer. Inst. Chem. Engrs. 27, 203 [1931].

11 W. E. Browning, JR., R. F. Roberts, C. E. Miller, Jr., and R. P. SHIELDS, ORNL-3547, 42 [1964]. 

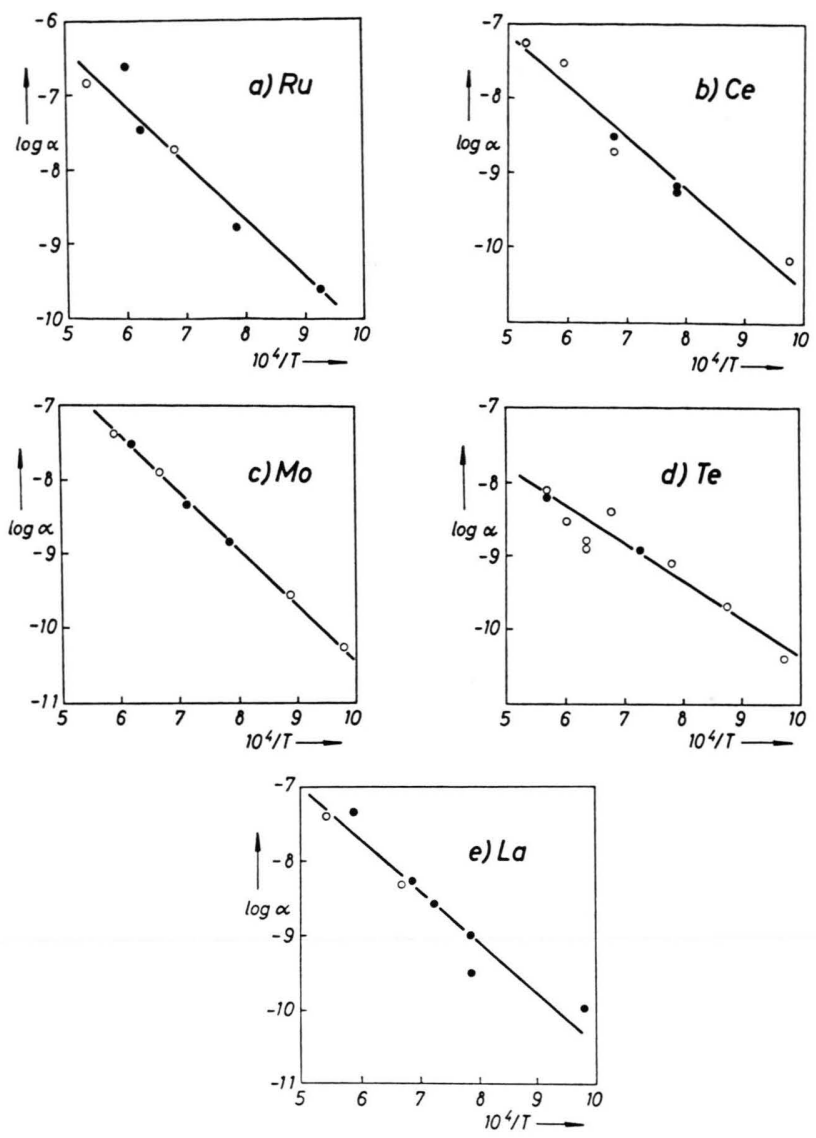

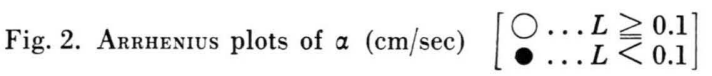

behavior of fission products at much higher temperatures have been reported by the ORNL group ${ }^{12,13}$.

In publications ${ }^{14,15}$ concerning the release of fission products into reactor coolants from defected fuel elements, it was observed that the release rates of fission products other than the rare gases are much lower than predicted from the diffusional be-

\begin{tabular}{|c|c|c|c|}
\hline Elements & $\begin{array}{c}E_{\alpha} \\
(\mathrm{Cal} / \mathrm{g} \cdot \text { atom })\end{array}$ & $\begin{array}{c}\text { Melting } \\
\text { points }\left({ }^{\circ} \mathrm{C}\right)\end{array}$ & $\begin{array}{c}\text { Boiling } \\
\text { points }\left({ }^{\circ} \mathrm{C}\right)\end{array}$ \\
\hline $\mathrm{Ru}$ & 34 & 2,500 & 4,100 \\
$\mathrm{Mo}$ & 37 & 2,620 & 4,800 \\
$\mathrm{Te}$ & 22 & 452 & 1,390 \\
$\mathrm{Ce}$ & 30 & 804 & 1,400 \\
$\mathrm{La}$ & 30 & 920 & 4,500 \\
\hline
\end{tabular}

Table 2. Activation energy of evaporation.

haviour, while $\mathrm{Kr}$ and $\mathrm{Xe}$ release was found to follow the diffusional mechanism ${ }^{16}$. Table 3 seems to explain the fact fairly well, although, of course, the whole of these in-pile behaviours are too complicated to be interpreted by single mechanism.

(2) In the aforementioned treatment the diffusion constants previously obtained by the use of single crystals were regarded as good approximate values, since $L=\infty$ was believed to hold for most of the fission products examined, the reason being as follows.

(i) The variation of $F$ with $\sqrt{t}$ follows equ. (1) except in case of La, where the agreement of measurement with equ. (2) is not so good. The results were discussed previously ${ }^{3}$.

(ii) In evaluating $\alpha$ values in Fig. 2, the $\alpha$ 's were determined by using $D$ values for $L$ values above 0.1 . The $\alpha$ values plotted as hollow circles agree well with the points for $L<0.1$ which were calculated directly from equ. (3) without use of $D$ (solid circles). This agreement establishes the self-consistency of the present treatment.

\section{Acknowledgement}

The author is greatly indebted to Dr. N. Or of Toshiba Central Research Lab. for his helpful discussions and continual experimental collaboration. He also wishes to thank Mr. Y. Matsushima of this laboratory for performing the necessary computations with the electronic computor, IMB-7090.

\begin{tabular}{|l|c|c|c|c|c|c|}
\hline \multicolumn{1}{|c|}{ Elements } & $\mathrm{Ru}$ & $\mathrm{Ce}$ & $\mathrm{Mo}$ & $\mathrm{Te}$ & $\mathrm{La}$ & $\mathrm{Xe}$ \\
\hline$\alpha(\mathrm{cm} / \mathrm{sec})$ & $1.6 \times 10^{-8}$ & $4.0 \times 10^{-9}$ & $1.0 \times 10^{-8}$ & $1.7 \times 10^{-9}$ & $7.2 \times 10^{-9}$ & - \\
$D\left(\mathrm{~cm}^{2} / \mathrm{sec}\right)$ & $5.3 \times 10^{-11}$ & $3.6 \times 10^{-12}$ & $3.7 \times 10^{-12}$ & $3.1 \times 10^{-13}$ & $1.5 \times 10^{-11}$ & $1.4 \times 10^{-12}$ \\
$L(=a \alpha / D)$ & 0.03 & 0.11 & 0.27 & 0.55 & 0.48 & 0 \\
$\begin{array}{c}F \text { for present experimental } \\
\text { conditions (\%) }\end{array}$ & 25 & 6.7 & 14 & 2.9 & 12 & 72 \\
Relative release & 1 & 0.27 & 0.56 & 0.12 & 0.48 \\
\hline
\end{tabular}

Table 3. Relative release at $1200^{\circ} \mathrm{C}$ predicted from $\alpha$ values for $a=1.0 \times 10^{-4} \mathrm{~cm}$ and $t=600 \mathrm{sec}$.

12 ORNL-3547, Part I [1964].

13 ORNL-3591, Part IV [1964].

14 R. Ehrenreich, WAPD-TM-159 [1959].

15 J. A. L. Robertson, A. S. Bain, A. H. Booth, J. W. Howleson, W. G. Morrison, and R. F. S. Robertson, Proceedings of the Second International Conference on the Peaceful
Uses of Atomic Energy, Geneva 1958, Vol. 6, p. 655, United Nations 1958.

16 B. Lustman, $\mathrm{UO}_{2}$, Properties and nuclear applications (Ed. J. Belle), 9. 4. 10 (b) p. 528, U.S. Atomic Energy Commission [1961]. 